Volume 14 - Número 2 - ago/dez de 2019

\title{
A MULTIMODALIDADE E AS MÚLTIPLAS SEMIOSES DO DIZER: A (DES)CONSTRUÇÃO DE SENTIDO EM UM ANÚNCIO PUBLICITÁRIO DO MEC
}

\author{
MULTIMODALITY AND MULTIPLE SEMIOSES OF SAYING: THE \\ (DE)CONSTRUCTION OF MEANING IN A MEC ADVERTISEMENT
}

\author{
Nelma Teixeira da Silva ${ }^{1}$
}

\begin{abstract}
RESUMO: Este artigo tem como objetivo tecer reflexões sobre as contribuições das multissemioses para a (des)construção de sentido no gênero publicitário, a partir dos estudos sobre os multiletramentos e os novos letramentos, que compreendem o uso de múltiplas linguagens, de diversos formatos e gêneros presentes em nosso cotidiano. Para tanto, selecionamos um anúncio publicitário digital do Governo Federal, da gestão 20192022, publicado pelo Ministério da Educação (MEC) em suas redes sociais, com vistas a explicitar como a produção de sentidos é construída na propaganda, procurando apresentar uma postura crítica em relação às ações e às dominações sociais existentes, a partir de uma breve análise da linguagem multimodal. Autores como Kress e van Leeuwen (1996), Kress (2003), Knobel e Lankshear (2003, 2006, 2007), Cope e Kalantzis (2009), Dionísio (2008), Rojo e Moura (2019), Bourdieu e Boltanski (1976), dentre outros, dão suporte à discussão. Concluímos que a presença das múltiplas semioses que integram os textos contemporâneos, e, mais especificamente, o gênero publicitário possibilita a veiculação massificada de discursos intencionalmente articulados que nos convidam à reflexão e ao exercício de práticas de leitura crítica, na escola de fora dela, sendo o letramento multimodal uma possiblidade para ampliação dos (multi)letramentos, já que aciona no indivíduo mecanismos de leitura que extrapolam a materialidade do texto.
\end{abstract}

PALAVRAS-CHAVE: Multimodalidade; Multissemioses; Multiletramentos; Novos letramentos; Gênero publicitário.

ABSTRACT: This paper aims to make reflections on the contributions of multisemioses to the (de)construction of meaning in the advertising genre. It is based on the studies of multiliteracies and new literacies that comprehend the use of multiple languages of different formats and genres, presence in our daily lives. To reach this end, we selected a digital advertisement from the Federal Government, of the management 2019-2022, published by the Ministry of Education (MEC) in their social networks in order to explain how the production of meanings is built in advertising, trying to present a critical stance in relation to the existing social actions and dominations from a brief analysis of the multimodal language. Authors such as Kress and van Leeuwen (1996), Kress (2003), Knobel and Lankshear (2003, 2006, 2007), Cope and Kalantzis (2009), Dionisio (2008), Rojo and Moura (2019), Bourdieu and Boltanski (1976), among others, support the discussion. We conclude from the study that the presence of the multiple semioses that make up contemporary texts, and, more specifically, the advertising genre enables the mass dissemination of intentionally articulated speech and invite us to reflect and to exercise critical reading practices, in and out of school, being multimodal literacy a possibility for the expansion of (multi)literacies since it triggers reading mechanisms that go beyond the text materiality.

KEYWORDS: Multimodality; Multisemioses; Multiliteracies; New literacies; Advertising Genre.

\section{Considerações iniciais}

A linguagem ocupa lugar central na vida humana e, considerando a presença indiscutível da linguagem imagética na sociedade contemporânea e sua crescente relevância nas novas práticas comunicativas, pesquisas sobre a multimodalidade baseadas no estudo da Semiótica Social (KRESS; VAN LEEUWEN, 1996), (KRESS, 2003), nos multiletramentos (COPE; KALANTZIS, 2009) e nos novos letramentos (KNOBEL; LANKSHEAR, 2003, 2006 , 2007) têm se tornado frequentes, uma vez que as novas tecnologias digitais avançam, contribuindo para o desenvolvimento e popularização de diferentes modos comunicativos

\footnotetext{
${ }^{1}$ Doutoranda em Letras do Programa de Pós-Graduação em Língua e Cultura, da Universidade Federal da Bahia. Docente da Educação Básica da Rede Estadual da Bahia. Membro do Grupo de Pesquisa "Núcleo de Estudos de Linguagem e suas Tecnologias" (NELT). E-mail: nelmateixeira@yahoo.com.br
} 
verbais e não verbais. Para além da preocupação em se analisar as imagens como textos propriamente ditos, também é relevante investigar os sentidos que são construídos precisamente pela combinação multissemiótica de diferentes signos. Assim, os modos de produzir e processar conhecimento ganharam novas configurações, o mundo digital, multimidiático e, sobretudo, online tem transformado a sociedade, e isso é possível porque hoje dispomos de novas tecnologias e ferramentas de leitura/escrita que convocam novos letramentos, (re)configurando os enunciados/textos em suas multimodalidades.

Considerando estes pressupostos, o presente artigo tem como objetivo tecer reflexões sobre as contribuições das múltiplas semioses para a produção de sentido no gênero publicitário, tomando por base os estudos sobre multiletramentos e os novos letramentos que compreendem o uso de múltiplas linguagens, de diversos formatos e gêneros, aliadas à diversidade e ao pluralismo cultural. Para isso, analisamos uma propaganda do Governo Federal, divulgada pelo Ministério da Educação (MEC) em suas redes sociais (Twitter, Instagram e Facebook), no dia 13 de Junho de 2019, que anunciava o prazo de encerramento das inscrições para concorrer a bolsas do PROUNI. A partir da sobreposição de imagem, recurso de linguagem escolhido pelo MEC para fazer a divulgação do anúncio, realizamos uma análise da linguagem multimodal, atravessada por uma leitura crítica, com vistas a explicitar as contribuições das múltiplas semioses para a (des)construção de sentidos na propaganda, em relação às ações e às dominações sociais existentes.

Para abarcar os pressupostos teóricos que subsidiam este estudo, abordamos, inicialmente, os conceitos de multimodalidade e a importância das múltiplas semioses na constituição da linguagem contemporânea, que cada vez mais têm sido influenciadas pelas tecnologias digitais da informação e comunicação. Em seguida, discorremos sobra a importância dos estudos sobre os multiletramentos e os novos letramentos e suas contribuições para que a escola se aproprie de estratégias que possibilitem ressignificar os modos de ensinagem. Nos tópicos seguintes, discorremos sobre o gênero publicitário e analisamos a articulação de imagens e palavras como constituintes da linguagem multimodal no processo de (des)construção de sentidos na propaganda do MEC. No seguimento final, esboçaremos algumas conclusões a partir do estudo realizado.

\section{A Multimodalidade e as múltiplas semioses nos modos de dizer}

$\mathrm{Na}$ sociedade contemporânea, é indiscutível a presença da multimodalidade, pois vivemos uma nova configuração de comunicação e de práticas discursivas. De acordo com Kress e van Leeuwen (1996), todo discurso é multimodal, porque, nos contextos sociais concretos de uso da língua, as pessoas se utilizam de formas de comunicação em que os significados comunicativos são construídos, compartilhados e desafiados por meio do uso combinado de vários modos de dizer (palavras, imagens estáticas e em movimento, cores, sons, formatos, disposição da grafia, gestos, padrões de entonação, escrita, a fala, etc.). Isso implica reconhecimento do entrelaçamento das múltiplas linguagens de diversos formatos e sistemas de signos envolvidos na construção dos textos multimodais.

Conforme Santos e Pimenta (2014, p. 297), a multimodalidade é uma perspectiva teórica baseada nos estudos linguísticos e na teoria da Semiótica Social. Por um lado, a Semiótica Social reaprecia a noção de signo da tradição saussuriana, herdada da escola semiótica de Paris que, conforme as autoras, nos anos de 1960 e 1970 estendeu as ideias de Saussure para os estudos em moda e fotografia (Barthes), cinema (Metz), música (Nattiez), entre outros. Ferdinando Saussure modificou o pensamento linguístico e semiótico do século $\mathrm{XX}$, provocando uma revisão generalizada da metodologia das ciências humanas. Com Saussure, começou-se a estudar a língua como um sistema a partir de conceitos como "significante", "significado", signos "arbitrário" e "motivado", eixos "paradigmático" e 
"sintagmático"; com dicotomias cujos termos opostos referem-se à ciência da linguagem, a Semiologia.

Por outro lado, a Semiótica Social apresenta uma abordagem da linguagem sustentada nas funções sociais da linguagem propostas por Michael Halliday (1973, p. 101), ao afirmar que a linguagem, no contexto da cultura, enquanto sistema semiótico, não é um código, mas antes um recurso com potencial gerador de produzir sentidos (HALLIDAY, 1978, p. 191192). Para autor, a Semiótica Social pode ser entendida como a ciência que se encarrega da análise dos signos na sociedade, cuja função principal é o estudo da comunicação dentro de um contexto social. Sendo uma abordagem que une significado e estrutura, a Semiótica Social preocupa-se com a linguagem em sua totalidade: forma e significado passam a ter a mesma importância dentro de um sistema que os vê como indissociáveis (Halliday, 2004, p. 15).

É neste entendimento que todos os signos ou recursos são considerados relevantes e que se distribuem em diferentes modos semióticos que interagem na construção e interpretação dos discursos, uma vez que os significados e os sistemas semióticos são moldados pelas relações de poder e que, à medida que o poder se desloca na sociedade, as línguas e outros sistemas de significados socialmente aceitos podem e devem mudar. A Semiótica Social é, portanto, o estudo das dimensões sociais dos significados e também o estudo do poder dos processos de significação e interpretação humanos na formação de indivíduos e sociedades. Ela centra-se nas práticas sociais de criação de significados de todos os tipos, de diferentes modos semióticos, (linguagem, imagem, música, gestos, arquitetura, dentre outros) que são realizados a partir de várias modalidades sensoriais (visual, auditiva, tátil, olfativa, gustativa e cinética), possibilitando o construto multimodal.

Kress e Van Leeuwen (1996, 2006), pioneiros nos estudos multimodais, entendem que as imagens se articulam em composições visuais também produzindo significados ideacionais, interpessoais e textuais. Para além do foco da Gramática Sistêmico-Funcional, de Halliday (2004) na linguagem verbal, os autores formulam a Gramática do Design Visual, estabelecendo uma perspectiva multimodal que envolve os significados de imagens e infográficos. Por esse ângulo, "os significados representacionais, os interativos e os composicionais operam simultaneamente em toda imagem, construindo padrões de experiência, interação social e posições ideológicas a partir das escolhas de qual realidade está sendo representada" (SANTOS; PIMENTA, 2014, p. 308).

Nesse viés, a Semiótica Social, aliada aos estudos em multimodalidade, visa investigar os principais modos de representação em função dos quais um determinado texto é produzido e realizado, além de compreender o potencial de origem histórico-cultural utilizado para produzir o significado de qualquer modo semiótico. Dessa maneira, a Semiótica Social e a multimodalidade buscam abordar as particularidades de cada modo semiótico, as regularidades de suas combinações e seus valores em contextos sociais específicos. A multimodalidade se configura como um campo de estudos que se destina a explorar as formas de significação modernas, o que abrange todos os modos semióticos inerentes aos processos de representação e comunicação (KRESS; VAN LEEUWEN, 2001).

Lemke (1988 apud GOMES, 2011, p. 64) mostra que os estudos da Semiótica Social "tornou-se fundamental para aqueles interessados em analisar aspectos dos textos que transcendiam os limites da língua. A Semiótica Social passou a ser a análise de sistemas de signos não estáticos e estruturas textuais de processos de significação socialmente situados". Yared (2015, p. 41) complementa que

o conceito mais fundamental da Teoria Semiótica Social, da Multimodalidade e do campo da Semiótica Social é o conceito de recurso semiótico, que amplia a ideia de signo e torna claro que o uso, o contexto e o interesse do autor são os fatores que definem o rumo funcional e, assim, o uso do recurso semiótico em determinado ato comunicativo com 
Volume 14 - Número 2 - ago/dez de 2019

determinado significado. $\mathrm{O}$ recurso semiótico é o conceito que redefine o signo como sendo motivado - e não arbitrário -, de acordo com o interesse do autor.

Assim, a multimodalidade realça a importância de se levar em consideração os diferentes modos de dizer, que podem ser representados por recursos imagéticos, sonoros e elementos linguísticos que se fundem e constroem novos sentidos para os discursos. Tomando por base esse pressuposto, ao propor uma leitura crítica do anúncio publicitário do PROUNI/MEC, questionamos: com qual intenção o autor dessa campanha publicitária usou da articulação verbo-visual? Que contexto está enunciado e qual o interesse do governo em publicá-lo nesta configuração? Perceberemos, pela análise, que não há nada de sutil nas escolhas discursivas do anúncio e que nas articulações multimodais, conforme pronuncia Fairclough (2001), há uma ligação íntima entre o conhecimento da linguagem, do discurso e do poder, de forma que os efeitos do discurso são planejados em detalhes pelo enunciador através das escolhas linguísticas. Disso decorre a necessidade atual e urgente de novos e múltiplos letramentos na escola, dada a possibilidade de ampliação do olhar crítico do aluno/leitor para captar as entrelinhas do que ele vê, lê, ouve e fala.

Nessa perspectiva, a inserção de (multi)letramentos nas práticas de ensino busca atender a uma demanda da sala de aula contemporânea: abranger situações reais de uso da língua, pois o tempo todo somos demandados a interpretar e articular as diversas modalidades semióticas presentes no texto por meio dos mais diversos gêneros discursivos. E o letramento multimodal, uma das propostas da pedagogia dos multiletramentos, está relacionado à manipulação dessas diferentes semioses, ou seja, novos modos mais amplos e mais dinâmicos de representação do discurso que vai além da linguagem verbal. Portanto, a leitura e análise de textos multimodais demanda que o sujeito esteja apto para compreender os vários modos de dizer que os textos contemplam, por meio da combinação e do arranjo de diferentes linguagens, com recursos e mecanismos de representações potencialmente expressivas, significativas e comunicativas.

Um dos fatores que tem ampliado a presença da multimodalidade nos textos contemporâneos é o crescimento da comunicação em rede, que sugere novas linguagens capazes de mudar, inclusive, a dinâmica das relações sociais. As novas tecnologias da comunicação e informação (NTDIC) estão mudando a forma como utilizamos a escrita e a leitura, visto que a realidade vivenciada exige ações imediatas no sentido de compreender como texto verbal e imagens realizam significados culturais. Segundo Nascimento et al. (2011, p. 532), imagens e textos verbais devem ser entendidos como um sistema semiótico, ou seja, conjunto de signos socialmente compartilhados por princípios e regularidades, que se utiliza para representar experiências e negociar a relação com os outros. Essa nova reconfiguração social da linguagem, em termos de produção de sentido, reverbera para uma noção ampliada do conceito de texto, ou seja, "qualquer instância comunicativa, em qualquer modo semiótico ou qualquer combinação de modos" (KRESS, 2003, p. 48), contrariando a visão de texto configurado apenas como meio de linguagem verbal escrita. Essa concepção é sustentada por Dionísio (2008), ao destacar que as novas tecnologias têm contribuído de maneira exponencial para a ampliação do conceito de texto, uma vez que

imagem e palavra mantêm uma relação cada vez mais próxima, cada vez mais integrada. Com o advento das novas tecnologias, com muita facilidade se criam novas imagens, novos layouts, bem como se divulgam tais criações para uma ampla audiência. Todos os recursos utilizados na construção dos gêneros discursivos exercem uma função retórica na construção de sentidos dos textos. Cada vez mais se observa a combinação de material visual com a escrita; vivemos, sem dúvida, numa sociedade cada vez mais visual (DIONÍSIO, 2008, p. 41) 
Volume 14 - Número 2 - ago/dez de 2019

É cada vez mais comum que as imagens se integrem ao texto, no qual língua e imagem trabalham juntas, convergindo para o propósito de fazer significar. De acordo com Kress e Van Leeuwen (1996, p. 21), quando queremos comunicar algo, procuramos modos de fazê-lo com a premissa de que apenas um modo possa não ser suficiente, e a justaposição de imagens e textos, por exemplo, pode ser usada para melhor exemplificar ou comunicar, sendo disposta de acordo com a pretensão, com o objetivo comunicativo do produtor, de forma que possa ser mais informativo para o leitor, embora haja maneiras convencionais para usá-la.

Imagens fixas ou em movimento, como por exemplo emoji ${ }^{2}$, gif ${ }^{3}$, stickers $^{4}$ e meme $^{5}$ tornaram-se muito populares nas trocas de mensagens instantâneas via WhatsApp, Facebook, Instagram, Telegram e Twitter. Carinhas com expressões variadas, mãozinhas, coraçõezinhos e outras figuras, acompanhadas ou não de texto, avolumam o "dicionário" das conversas eletrônicas, fixando-se como legítimos recursos de fala/interação para o efeito de presença: através dessas imagens fazemos o outro "ver" as nossas reações e emoções, como na conversa presencial, e em muitos casos, são os protagonistas em eventos comunicativos. Para Gomes (2011, p. 13)

a publicação de textos em blogs, sites e em outras redes de relacionamento tem permitido a um número cada vez maior de pessoas exercitarem a prática da escrita, desde postagens de comentários a produção artísticas ou acadêmicas, por lazer, trabalho ou qualquer outra razão. Dadas às facilidades dos ambientes digitais, os textos vêm acompanhados de imagens ilustrativas, ou as imagens é que vêm com textos explicativos. Tudo isso num visual diferente, que ultrapassa os limites do que chamamos de redação e entra no campo do design, da produção visual.

O ciberespaço torna-se, assim, um local de intensa produção textual, em que os sujeitos recepcionam, criam e recriam práticas de leitura e escrita a partir da multimodalidade. Santaella (2007, p. 194) afirma que "nenhuma tecnologia da comunicação borra ou elimina as anteriores, juntam-se na composição intrincadíssima de uma cultura hiper-híbrida". Assim, todos os recursos semióticos (escrita, imagem, cor, som, etc.) são capazes de gerar significados, porém, não da mesma forma. Eles nos permitem fazer coisas diferentes em relação às mesmas questões, gerando um significado mais rico ou completo em relação àquele gerado por um único modo.

Essa evolução dos modos de comunicar a partir das tecnologias digitais afeta positivamente a educação, implicando, sobretudo, em uma mudança de paradigma nos modos de ensinar. Ou seja, a escola deve se aproximar das práticas de leitura e escrita que convirjam para a realidade atual da comunicação e informação marcada, sobretudo, pelos textos multimodais contemporâneos, investindo em metodologias que levem em consideração os

\footnotetext{
${ }^{2}$ Emoji é um símbolo de origem japonesa, composta pela junção dos elementos "e" (imagem) e "moji” (letra) e é considerado um pictograma ou ideograma, ou seja, uma imagem que transmite a ideia de uma palavra ou frase completa.

${ }^{3}$ Gif é um formato de imagem que pode compactar várias cenas e com isso exibir movimentos. A sigla GIF significa Graphics Interchange Format, que na tradução literal para português seria formato para intercâmbio de gráficos. É usado nas redes sociais para deixar as mensagens mais criativas, animadas e agradáveis para o leitor.

${ }^{4}$ Stickers são imagens mais elaboradas que os emojis e os emoticons. Por serem ilustrações mais complexas, os stickers permitem que os usuários expressem melhor suas emoções. Podem ser personalizados a partir de fotografias.

${ }^{5} \mathrm{O}$ meme é um termo criado pelo escritor Richard Dawkins cujo significado é um composto de informações que podem se multiplicar rapidamente. $\mathrm{O}$ meme pode ser uma ideia, um conceito, sons ou qualquer outra informação que possa ser transmitida rapidamente.
} 
Volume 14 - Número 2 - ago/dez de 2019

usos que os alunos já fazem de textos compostos por imagens, sons e palavras em suas práticas sociais cotidianas, uma vez que a escrita está passando por uma ressignificação, englobando o planejamento e a articulação de diferentes linguagens, formando um "grande mosaico semiótico" com o objetivo de atingir um propósito comunicativo.

\section{Da necessidade de novos (multi)letramentos}

A multiplicidade de usos da linguagem, em diferentes contextos sociais, tem motivado pesquisadores da educação e da linguagem a empreender pesquisas para compreender o uso das novas práticas de linguagem na formação dos aprendizes. Estudos sobre multiletramentos, realizados desde 1996 pelo Grupo Nova Londres (GNL - New London Group), já apontavam para a necessidade de uma nova forma de ensinar e de aprender mais condizentes com as demandas do novo mundo do trabalho, da cidadania e da vida que desse conta dos novos letramentos emergentes na sociedade contemporânea. Para os pesquisadores do GNL, os efeitos da globalização e a presença de novas tecnologias da informação e comunicação tinham impacto não só na economia e nas relações de trabalho, em que o capital humano se valorizou (as multi-habilidades, a flexibilidade, criatividade e inovação passaram a ser pontos-chave para o mercado), como também na diversidade cultural e linguística das populações e nos textos, que já não eram essencialmente escritos, mas acompanhados de uma pluralidade de linguagens que eles denominaram multimodalidade. Para Cope e Kalantzis (2009, p. 19), multiletramentos envolvem a capacidade de compreender e de produzir textos compostos por muitas linguagens (multissemioses). Corroborando com os autores, Rojo e Moura (2019, p. 20), complementam que o conceito de multiletramentos "é um conceito biforme: aponta, a um só tempo, para a diversidade cultural das populações em êxodo e para a diversidade de linguagens dos textos contemporâneos, o que vai implicar em uma explosão multiplicativa de letramentos, que se tornam multiletramentos".

Desenvolvendo estudos nessa direção, Knobel e Lankshear (2003, 2006, 2007) sentem a necessidade de ampliar o sentido do termo letramento para "novos letramentos". Conforme os autores, os novos letramentos, também partem da premissa de que os fenômenos de letramento são práticas sociais e situadas culturalmente, emergem de acordo com as mudanças nas formas de linguagens, comunicação e nos recursos tecnológicos, e devem ser investigados e explorados de acordo com seus contextos sociais, culturais, políticos, econômicos e suas práticas históricas, aos quais estão ligados integralmente. Sendo assim, os autores sugerem uma ampliação das práticas de letramentos convencionais para além do desenvolvimento da leitura e escrita, tendo em vista o universo aberto pelas novas tecnologias digitais da comunicação e informação.

Entretanto, conforme postula Lankshear e Knobel (2007, 2013), nesse novo cenário uma inquietação acompanha os professores: como possibilitar aos alunos espaços de aprendizagem inovadores, otimizar o tempo da aula e transformar informações em conhecimento, em meio à imensa complexidade, simultaneidade e velocidade, próprios dos novos letramentos? O mundo digital requer lidar com conceitos e questões que envolvam saber, opinar, criticar, justificar conforme as demandas que esses novos espaços têm criado. Por isso, mais do que nunca, professores precisam do conhecimento que seus próprios alunos estão consumindo, produzindo, interagindo, remixando para ressignificar suas práticas escolares.

Em suma, tomando por base esses pressupostos, parece evidente que a escola precisa apropriar-se do trabalho com as múltiplas linguagens, mobilizando novos (multi)letramentos, bem como desenvolver competências linguísticas comunicativas e multimodais, o que exige uma pedagogia culturalmente sensível em sala de aula. Para isso, o professor precisa estar preparado para definir, compreender e fundamentar a sua prática de ensino. Dessa forma, 
Volume 14 - Número 2 - ago/dez de 2019

trabalhar o uso social do gênero publicitário em sala de aula pode proporcionar a construção de sentidos do discurso de forma crítica, criativa, desafiadora e em colaboração, possibilitando a interação e o uso de diferentes linguagens que envolvem e desafiam os alunos a usarem diferentes recursos semióticos para se comunicar, como propõe os estudos dos multiletramentos e dos novos letramentos.

\section{$4 O$ gênero publicitário}

O gênero publicitário é desenvolvido, reproduzido e transformado por meio das práticas sociais e discursivas das mídias. Um ponto de destaque nos textos publicitários multimodais é certamente seu hibridismo inerente à relação entre o escrito, o oral e o visual, o que demonstra que esse gênero tem acompanhado as demandas socioculturais contemporâneas em relação ao uso de múltiplas linguagens, ou seja, na linguagem multimodal, componentes visuais, digitais e sonoros passam a ter um papel fundamental na construção ou desconstrução de sentidos do discurso.

Sandmann (1999), diferencia o termo publicidade de propaganda: aquele é usado para se referir à venda de produtos ou serviços; este tem um sentido mais abrangente, serve tanto para a divulgação de uma mensagem, buscando influenciar opiniões ou obter adesão para uma ideia ou doutrina, como também no sentido de publicidade. Entretanto, neste artigo, os termos publicidade e propaganda são usados como sinônimos. E para este estudo focamos na publicidade institucional.

Conforme a Instrução Normativa $\mathrm{n}^{\mathrm{o}}$ 2, de 20 de abril de 2018 em vigor, a publicidade dos órgãos ligados ao Governo Federal compete ao setor de comunicação do Poder Executivo Federal, que classifica essa publicidade em: a) publicidade de utilidade pública; b) publicidade institucional; c) publicidade mercadológica; e d) publicidade legal. Assim, conforme a IN n ${ }^{\circ}$, a publicidade institucional destina-se a "divulgar atos, ações, programas, obras, serviços, campanhas, metas e resultados dos órgãos e entidades do Poder Executivo Federal, com o objetivo de atender ao princípio da publicidade, de valorizar e fortalecer as instituições públicas, de estimular a participação da sociedade no debate, no controle e na formulação de políticas públicas e de promover o Brasil no exterior. "

Assim, a publicidade institucional pode ser conceituada como uma forma de propaganda que não se refere a um produto específico, e sim a órgãos, empresas ou instituições, visando à disseminação de ideias com o intuito de moldar e influenciar a opinião pública, para motivar comportamentos desejados por essas entidades sociais ou provocar mudanças em sua imagem pública. Além disso, a propaganda institucional

leva em conta o comportamento da população com o objetivo de fidelizar o cidadão e de universalizar valores, visando à manutenção das relações de poder. Ela é semiótica e social ao mesmo tempo, porque constrói uma representação com a linguagem e com outros sistemas semióticos, ela atua (ordenando seu desempenho) nas relações sociais, e também busca moldar o comportamento das pessoas, baseada em certos conhecimentos culturais e linguísticos, além de construir a identidade do viewer/telespectador por meio da emotividade e do afeto. (YARED, 2015, p. 28)

Este tipo de publicidade, é utilizada também para criar no público um estado de confiança, influenciando-o a aderir aos valores e às ideologias da instituição anunciante. Com isso, a publicidade institucional,

é uma ação comunicativa e estratégica, porque exibe construções (textos) emanadas das práticas sociais, instanciados com recursos linguísticos e 
Volume 14 - Número 2 - ago/dez de 2019

semióticos que podem influenciar os valores do interlocutor ou mesmo provocar efeitos como a adesão político-partidária por meio do envolvimento emocional graças ao uso de recursos e signos moldados histórica e culturalmente, graças à natureza assimétrica da interação (YARED, 2015, p. 29).

O anúncio publicitário institucional é encontrado em variados suportes. A acelerada revolução digital impulsionou e contribuiu para a sofisticação da linguagem publicitária, a qual se faz presente, tanto nas mídias impressas como nas mídias digitais em geral (Instagram, Facebook, Telegram, Twitter, dentre outras).

Especialmente quando veiculado em mídias digitais, o gênero publicitário, geralmente, apresenta uma linguagem popular como estratégia de aproximação com o público, igualando as vozes e as posições representadas. Conforme Kress e van Leeuwen (2003), esse efeito de proximidade, de igualdade e de confiança na relação com os atores sociais permite melhor aceitação do que é proposto na mensagem. Além disso, Magalhães (2005) categoriza a publicidade como um poderoso discurso da pós-modernidade, tendo em vista o contexto de promoção de uma cultura do consumismo, o que implica a produção de necessidades e de desejos, em especial, pela mobilização da fantasia, na perspectiva de que o gênero publicitário constrói estilos de ser e de viver, identificações e representações identitárias.

Como prática de interação social midiatizada, a atividade publicitária produz discursos que se materializam em textos geralmente polissêmicos, cuja pluralidade de sentidos que emitem tem como propósito persuadir seus leitores consumidores. O texto publicitário é resultado, pois, da união de vários fatores: psicológicos, sociais e econômicos, como também do uso de efeitos retóricos, recursos imagéticos e icônicos aos quais não faltam as figuras de linguagem e estilísticas, as técnicas argumentativas e os mecanismos de persuasão entre outros. Este gênero provoca reações emocionais no leitor e usa diversos meios para convencer, alterar atitudes e comportamentos. Para isso, palavras e imagens camuflam ideologias que são conduzidas sob o efeito da argumentação, influenciando na manipulação dos elementos linguísticos e icônicos direcionados para a persuasão. Sandmann (1999, p. 34) acredita que o texto publicitário é, também, reflexo e expressão da ideologia e de valores dominantes, manifesta a maneira de ver o mundo e a sociedade em certo espaço da história. Neste sentido, o discurso publicitário pode ser visto como um "termômetro social", retratando a "consciência possível de um grupo social". O discurso publicitário institucional se caracteriza, enfim, por ter uma função social específica, não só "pressentida", mas explicitada (TRAVAGLIA, 2001, p. 2-3). É o que poderemos constatar a partir da leitura multimodal da propaganda, a seguir.

\section{A articulação de imagens e palavras: (des)construindo sentidos na propaganda do MEC}

A peça publicitária que escolhemos como objeto de leitura crítica a partir da multimodalidade, foi um anúncio publicitário, divulgado pelo Ministério da Educação (MEC) em suas redes sociais. Trata-se de um anúncio que provocou muita polêmica devido ao impacto causado pela composição da imagem da propaganda. O modo visual do anúncio mostra uma mão branca segurando um diploma em contraste com uma estudante negra que aparece apontando para o tão almejado diploma, conforme imagem abaixo: 
Volume 14 - Número 2 - ago/dez de 2019

Figura 1:Propaganda do Ministério da Educação - Governo Federal

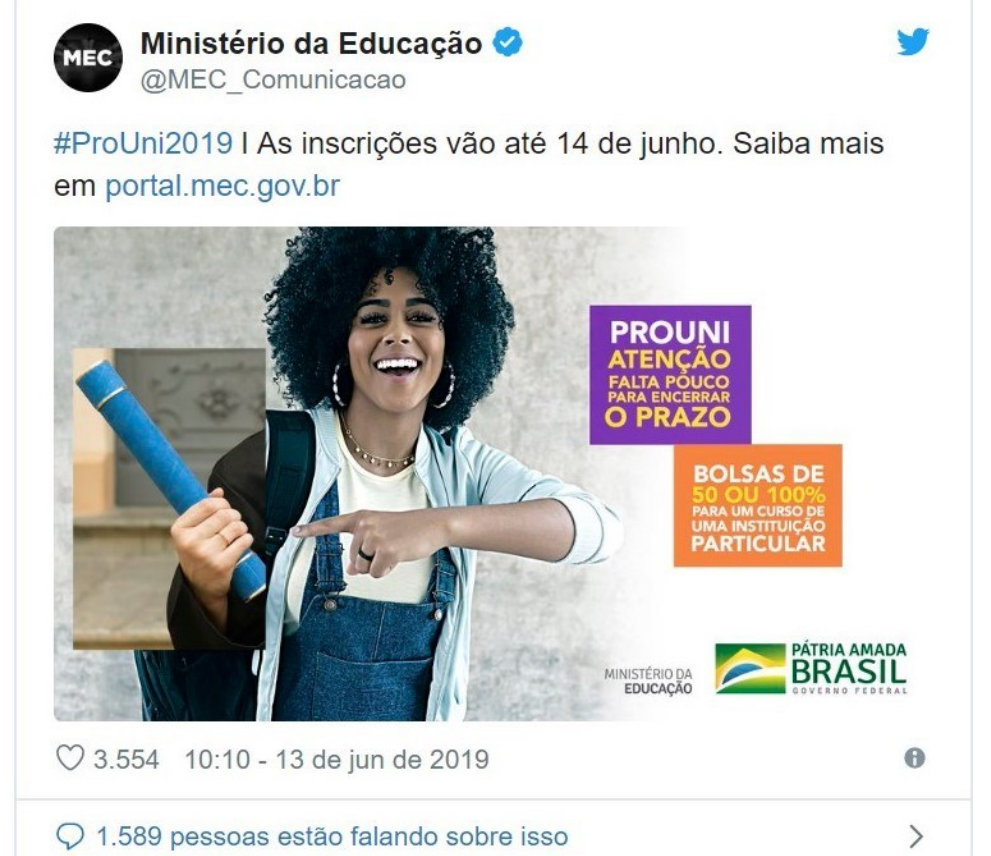

Fonte: Twitter do Ministério da Educação - Disponível em https://twitter.com/MEC_Comunicacao/status/1139158021723033600

A propaganda em questão classifica-se como um anúncio publicitário institucional vinculada ao Governo Federal atual (Gestão 2019-2022), como comprova a logomarca no canto inferior direito da imagem. Foi postada pelo Ministério da Educação (MEC) no dia 13/06/2019, em suas redes sociais (Twitter, Instagram e Facebook), mídias digitais de comunicação virtual utilizadas, compartilhadas e escolhidos pelo autor da peça publicitária. $\mathrm{O}$ referido anúncio, acima reproduzido com print da página do Twitter, que teve como propósito comunicativo a divulgação do encerramento das inscrições para concorrer a bolsas para cursos de graduação por meio do Programa Universidade para Todos (Prouni), foi acusado de racismo na internet, sendo alvo de protestos e muitas críticas pelos internautas e pela mídia em geral. Já nos primeiros instantes da postagem, os comentários da plataforma Twitter ultrapassaram mais de mil e quinhentos comentários, como mostra o rodapé da imagem acima, sem contar as curtidas, comentários e compartilhamentos nas outras redes sociais do MEC. A leitura do anúncio feita pela da maioria dos seguidores na página virtual sugere uma estudante que, após ganhar uma bolsa de estudos, entra na faculdade como negra e quando consegue se formar passa a ter a pele branca, como pode ser constatado nos comentários abaixo:

Figura 2: Comentários dos seguidores do Twitter do MEC, entre os dias 14 e 20 de Junho de 2019 
Volume 14 - Número 2 - ago/dez de 2019

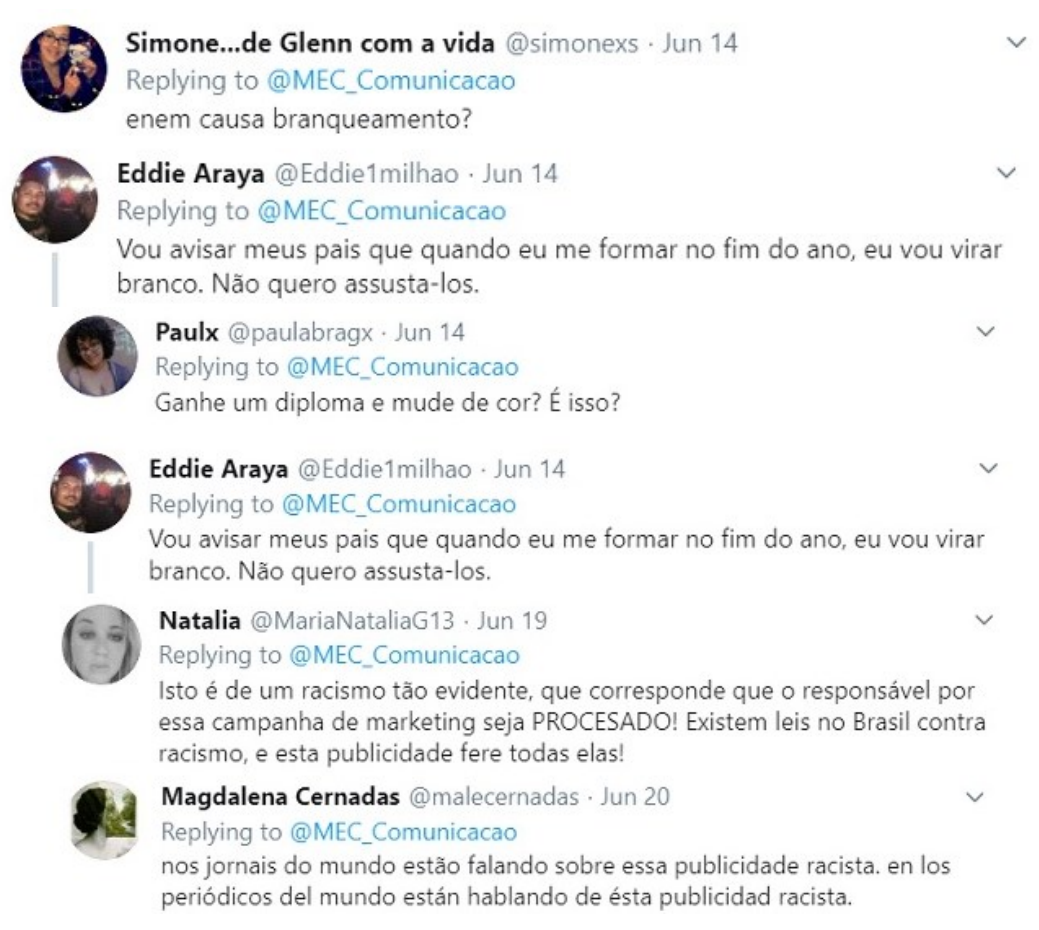

Considerando a leitura multimodal do anúncio pela perspectiva da maioria dos internautas, vemos que o conjunto dos modos semióticos permite essa (des)construção de sentido, uma vez que a composição imagética feita a partir do efeito de colagem sobreposta, recurso da linguagem visual utilizada pelo MEC na publicidade, põe em evidência o preconceito racial. $\mathrm{Na}$ imagem da jovem que protagoniza o anúncio, vemos claramente: do lado esquerdo do post, um braço vestindo elegantemente um traje social formal de cor preta que destaca a mão branca segurando um canudo de diploma, objeto de contemplação e desejo dos estudantes, sugerindo alguém que conseguiu se formar no ensino superior; do lado direito, evidencia-se o contraste com o corpo negro da jovem, vestida de forma despojada jeans, camiseta e mochila, denotando a informalidade típica dos estudantes.

Uma mirada crítica no discurso enunciado por trás dessa montagem imagética provocativa, que impacta pela estranheza da dualidade preto/branco e padrão/informal, revela a força da dimensão política do poder simbólico explícito nesses detalhes. O referido anúncio parece reforçar concepções da superioridade racial que remetem ao nosso passado colonial escravocrata e está fundamentado em discursos que precisam ser problematizados em sala de aula, uma vez que influenciam não só a visão dos jovens que estão se preparando para ingressar no ensino superior, como também toda a sociedade que acompanhou a propaganda, através das redes sociais, criando uma representação ilusória da formação inicial dos jovens, impondo, ao que parece, uma superioridade do branqueamento simbólico da população negra e o desrespeito para com as identidades raciais. Diante de um discurso violento como esse, é preciso questionar em sala de aula com qual propósito ideológico o Governo Federal fez essa campanha publicitária, uma vez que foi publicado em redes sociais de grande acesso, principalmente à população jovem. Em comentário ao post do MEC no Instagram, Lilia Moritz Schwarcz deixa claro que "o determinismo racial e as políticas do branqueamento não são mais teorias oficiais, mas fazem parte da poderosa "teoria do senso comum" que continua a circular no Brasil, de forma sinuosa".

Evidenciamos também no anúncio em questão que o Governo Federal agride a própria legislação que regulamenta atualmente a publicidade dos órgãos e entidades do Poder Executivo Federal, ao desrespeitar os dispositivos abaixo: 
Volume 14 - Número 2 - ago/dez de 2019

"No desenvolvimento das ações e na criação dos conteúdos das peças publicitárias, os órgãos e entidades deverão observar as disposições do Decreto ${ }^{\circ}$ 6.555/2008 e as seguintes diretrizes, respeitadas as características de cada ação:

(...) VIII - promover a autoestima dos brasileiros."

Art. $2^{\circ}$ do Decreto ${ }^{\circ} 6.555$, de 8 de setembro de 2008:

"No desenvolvimento e na execução das ações de comunicação previstas neste Decreto, serão observadas as seguintes diretrizes, de acordo com as características de cada ação:

(...) IV - valorização da diversidade étnica e cultural e respeito à igualdade e às questões raciais (...)"

Nesta campanha publicitária, o autor parece ter combinado recursos semióticos que refletem apenas seus interesses ideológicos e em nenhum aspecto promovem a autoestima dos brasileiros, como reza o Artigo $6^{\circ}$ acima, e sim o oposto, emitindo o entendimento de desvalorização do contexto sociocultural, da diversidade étnica e das questões raciais referido no Art. $2^{\circ}$, inciso IV citado acima. O comentário em tom desolador, subserviente e conformado, reproduzido abaixo, de um seguidor do Twitter, que pela foto do perfil mostra ser um estudante negro, comprova esse deslize do MEC:

Figura 3: Comentário de seguidor do Twitter do MEC

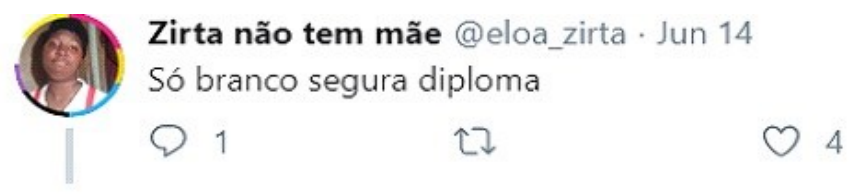

A esse respeito, Maia (2019, p. 69) assevera que dividir seres humanos em cores pode ser compreendido como uma produção violenta de sofrimento, já que "o ideal de branqueamento continua a se perpetuar e a dividir a própria população brasileira entre o branco, o menos branco, o bege, o marrom, o "queimado", o vermelho... e o negro! A cada tom mais escuro se institui potencialmente menos humanidade e mais sofrimento. Em contrapartida, a cada tom mais claro se afirma mais privilégio e um modelo hegemônico de Ser Humano". Assim, entender os "cinquenta tons de preto" enquanto reflexo da política do branqueamento faz refletir sobre como os efeitos dessa política se atualizam na contemporaneidade, dificultando que o negro possa ser negro, que possa reconhecer sua ancestralidade, sua cultura e seus direitos, inclusive que possa se sentir confortável no seu próprio corpo.

Examinando a justaposição das multissemioses que compõe o sentido global do anúncio a partir do diálogo entre o verbal e o imagético presentes no anúncio, podemos inferir que outro grande problema aparente nessa publicidade é a reiteração e consequente naturalização da desigualdade social e de oportunidades, como se isso não fosse um problema a combater, a criticar, sobretudo, pelo discurso do Ministério da Educação. A caixa de texto colorida em laranja "BOLSAS DE 50 OU 100\% PARA UM CURSO DE UMA INSTITUIÇÃO PARTICULAR" (grifo meu) chama a atenção para as palavras "bolsa" e "instituição particular" fazendo referência aos estabelecimentos privados de ensino superior. Pelo que temos acompanhado através da mídia, a ênfase dada às palavras em destaque mostra que o financiamento da educação está no alvo dos interesses privatistas defendidos pelo atual Governo Federal. As ações tomadas até agora na área não têm priorizado um processo educacional que visa interromper as desigualdades no acesso à educação e estabelecer um currículo que produza resultados mais democráticos para as minorias. Pelo contrário! Essa 
Volume 14 - Número 2 - ago/dez de 2019

"arquitetura" contribui para dificultar o acesso e permanência dos estudantes de baixa renda no ensino superior e tende a transformar a educação pública brasileira em mercadoria. Exemplo disso é o "Programa Future-se" do MEC que se encontra em fase de consulta pública e tem sido alvo de intensas críticas por parte da comunidade acadêmica e de estudiosos da educação.

Dessa forma, a publicidade é um dos instrumentos utilizados pelo sistema governamental para reproduzir e garantir a manutenção da ideologia dominante, como forma de legitimar suas ações. Bourdieu e Boltanski (1976, p. 11), em relação ao discurso dominante, afirma que

Ele [o discurso dominante] tem por função primeira orientar uma ação e manter a coesão dos executantes reforçando, pela reafirmação ritual, a crença do grupo na necessidade da legitimidade de sua ação. Convertidos e instruídos no mesmo dogma e dotados dos mesmos esquemas de pensamento e de ação, das mesmas disposições éticas e políticas, podem fazer a economia da prova, a totalização e o controle lógico, aceitando explicar somente os pontos nos quais sua ação encontra a resistência ou o eco.

Nesse sentido, a função do discurso dominante é, pela repetição, tornar as ações inquestionáveis e sem resistência, de forma que haja uma concordância generalizada sobre o que é bom para todos, o que é adequado para as pessoas na sociedade.

Isto posto, as múltiplas semioses possibilitam uma leitura crítica do texto envolvendo elementos que compõem o anúncio: as cores, o brilho da imagem contrastando com o fundo opaco, a escolha de ângulo centralizado e enquadramento frontal para a estudante sorridentemulher, estudante, negra, de baixa renda -, a mão branca com o diploma, a movimentação do corpo, os recursos linguísticos textuais das caixas de texto. Além desses, outros recursos multissemióticos incluem os elementos da plataforma do Twitter como o layout da página, os comentários dos seguidores, o perfil do MEC e o seu endereço eletrônico, a hashtag do Prouni e o uso de efeitos especiais possibilitado pela tecnologia, como o efeito de colagem das imagens sobrepostas. Todos esses elementos objetivaram servir aos propósitos comunicativos do enunciador. Entretanto, em conjunto, ajudaram também a captar o sentido do discurso homogeneizante e racista estampado na propaganda do MEC, à qual, após a publicação, a maioria dos seguidores responderam com reações de desaprovação, espanto, repulsa, nojo e ódio, como podemos constatar nos prints das interações abaixo, retiradas da página do MEC no Twitter:

Figura 3: Comentários dos seguidores do Twitter do MEC, entre os dias 14 e 15 de Junho de 2019

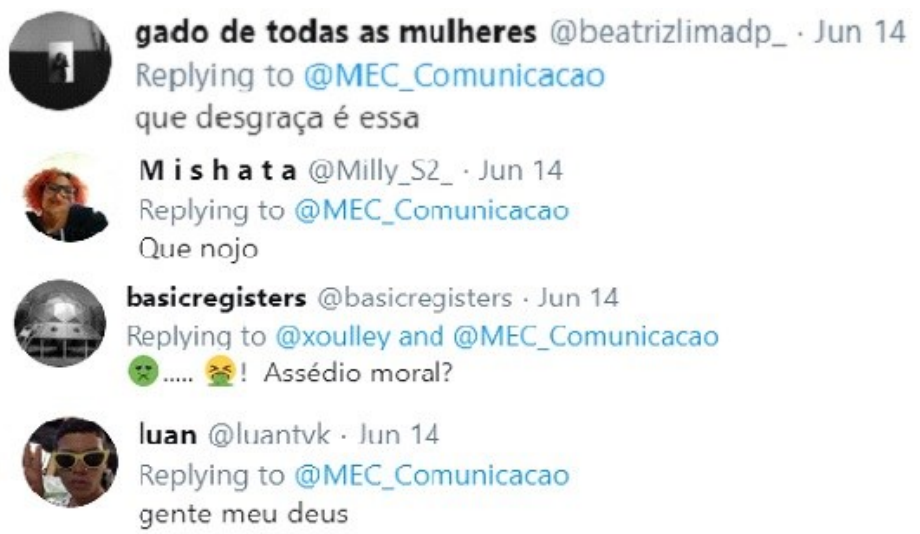


Volume 14 - Número 2 - ago/dez de 2019

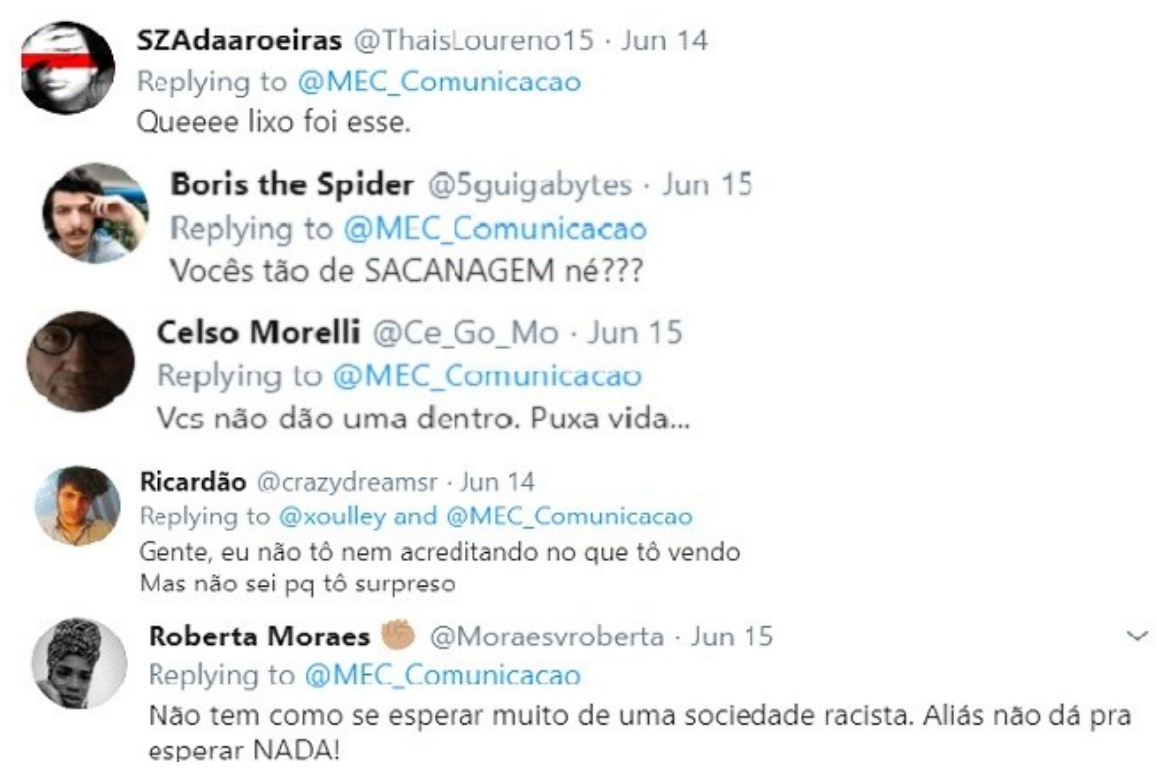

Nesse viés, o discurso do Governo Federal "não apenas reflete ou representa entidades e relações sociais, [ele] as constrói e[/ou] as constitui" (FAIRCLOUGH, 2001, p. 22). E essas construções, constituídas por um conjunto de recursos semióticos ideologicamente escolhidos (KRESS; VAN LEEUWEN, 1996) deixaram evidente os interesses do Governo Federal em instaurar políticas públicas que afetam negativamente os destinatários e o público potencial do anúncio (alunos do Ensino Médio, de baixa renda, das escolas públicas). Com base nessa (des)construção de sentidos possibilitada pela análise é possível perceber que, cada vez mais, há uma crescente multiplicidade e integração de modos de produção de significados na linguagem, conforme os estudos sobre os multiletramentos e novos letramentos apontam, mas chama a atenção, sobretudo, para a questão do olhar crítico que se deve ter ao fazer a leitura dos textos em suas múltiplas semioses no cotidiano.

Repensar a escola contemporânea implica levar em conta nos processos de ensinagem essas diferentes formas de leitura da realidade e reconhecer que nossos alunos de agora já não são os mesmos. Suas vivências são cada vez mais globais, o que demanda uma educação linguística que veja os alunos como agentes inseridos em práticas reais de letramento, ou melhor, de (multi)letramentos, dentro e fora do ambiente escolar, visto que as práticas de "letramento da letra" parecem não ser mais, por si só, suficientes para dar conta de preparar os alunos para os textos que se apresentam cada vez mais multifacetados na contemporaneidade.

A partir desse olhar, torna-se necessário repensar também sobre a própria condição do que é ser letrado no século 21, que não se restringe a ler e interpretar textos escritos; nem seria apenas reconhecer e transitar por diferentes espaços hipertextuais no mundo digital, mas, sobretudo, buscar compreender, interpretar e avaliar criticamente os diferentes mecanismos que regem a produção, reprodução e difusão do que circula no mundo digital.

Nessa perspectiva, a multimodalidade pode viabilizar a ressignificação das práticas de ensino a partir dos multiletramentos, trazendo uma perspectiva crítica através do uso de gêneros discursivos multimodais de ampla circulação na internet nas diferentes mídias digitais. Em sala de aula, o professor pode, por exemplo, provocar e sensibilizar os alunos a fazerem leituras críticas como essa a partir do uso dos próprios dispositivos eletrônicos, como o smartphone, por exemplo, e explorar as produções discursivas não só do gênero publicitário, mas também de gêneros discursivos de outras esferas de atividade enunciados nas mídias digitais. Levar para a aula reflexões críticas de discursos do cotidiano parece ser um caminho válido para mostrar como a construção multimodal de sentidos pode contribuir para o questionamento de forças ideológicas de poder e saber, com vistas à emancipação e transformação do indivíduo, estando "não apenas "no mundo', mas 'com o mundo"” 
Volume 14 - Número 2 - ago/dez de 2019

(FREIRE, 1981, p. 53), ou seja, sendo capaz de agir dentro e sobre seu contexto local e global, permitindo seu empoderamento com vistas a uma sociedade mais justa e democrática.

Ao buscar relacionar essas questões em uma propaganda do Governo Federal, procuramos apresentar uma postura crítica em relação às ações e às dominações sociais existentes, pois na maioria das vezes "os estereótipos e preconceitos atuam de maneira, pretensamente, invisível" (Lilia Moritz Schwarcz, em comentário ao post no Instagram) nos discursos. Assim, entendemos que as práticas de letramento têm um papel fundamental no processo de autonomia, processo esse que envolve esclarecimento, emancipação e formação da criticidade do cidadão.

\section{Considerações Finais}

As reflexões tecidas até aqui evidenciam que as relações entre multimodalidade e multiletramentos estão intrinsecamente estabelecidas, porque a leitura de textos multimodais/multissemióticos demanda habilidades ligadas aos multiletramentos, ou seja, as relações sociais presentes no mundo contemporâneo são construídas a partir de diferentes usos da linguagem, materializados por meio de gêneros discursivos. Interagir na sociedade da informação implica compreender as possibilidades de sentido presentes nos diferentes textos, depreender as especificidades da linguagem em seus diversos suportes e participar efetivamente das atividades presentes na realidade histórica, social e política da vida dessa sociedade.

Após a discussão estabelecida acerca da multimodalidade e das múltiplas semioses, percebemos que o gênero publicitário (e a mídia em geral), enquanto instituição social, não é uma entidade que existe fora do discurso, uma vez que tanto o dito em palavras quanto em imagens assume representações e ideologias, inclusive, como uma forma de controle social. Neste sentido, levando em conta o contexto sociopolítico que estamos vivenciando, parece evidente que a intenção do autor da campanha publicitária acima analisada, ao usar da articulação multissemiótica verbo-visual, foi promover o apagamento simbólico dos estudantes negros, sendo um reflexo do racismo institucional estampado na publicidade do MEC. Ou seja, a busca pela diversidade não é tão consciente e comprometida quanto se espera do ministério pilar para o desenvolvimento do país. O que se observa, na prática, é a segregação institucionalizada e sua permanência na estrutura da sociedade brasileira. E a mídia, apesar dos recentes avanços, ainda reforça os estereótipos contra a população afrodescendente.

Dito isto, reiteramos a necessidade de um ensino crítico que possibilite ao aluno ler os sentidos atravessados pelas materialidades discursivas, uma vez que a linguagem multimodal está presente em todos os tipos e gêneros textuais, integrantes legítimos das práticas sociais discursivas. Nesse sentido, inferimos que não se pode mais falar somente em letramentos, e sim, em multiletramentos e multimodalidades no ensino de gêneros discursivos na escola, enxergando o aluno como um ser digital, um (re)construtor da linguagem. Por isso, é necessário a escola se renovar e preparar os alunos para o funcionamento dessa sociedade cada vez mais digital, pois, se a sociedade muda, a linguagem a acompanha. Portanto, é preciso, nesse processo, que se abordem as capacidades/competências que a contemporaneidade exige acerca dos processamentos da leitura e da produção textual, ou seja, é fundamental que se fale sobre as práticas atuais de letramento e suas diversas relações com o mundo, o que requer a mobilização de gênero multimodais e práticas que abarquem o vasto contingente de elementos discursivos e semióticos materializados em sua organização estrutural. 
Volume 14 - Número 2 - ago/dez de 2019

\section{Referências}

BRASIL. Secretaria de Comunicação Social da Presidência da República (SECOM). Instrução Normativa $\mathbf{n}^{\mathbf{0}} \mathbf{2}$, de 20 de abril de 2018. Disponível em http://www.secom.gov.br/acesso-a-informacao/legislacao/arquivos-de-instrucoesnormativas/in2-secom-20-04-2018.pdf/. Acesso em 23.05.2019.

BOURDIEU, P.; BOLTANSKI, L. La production de l'idéologie dominante. Paris: Demopolis/ Raisons $\quad$ d'agir. $1976 . \quad$ Disponível em https://edisciplinas.usp.br/pluginfile.php/3958179/mod resource/content/1/La\%20production $\%$ 20de\%20lid\%C3\%A9ologie\%20dominante.pdf. Acesso em 23/08/2019.

COPE, Bill, KALANTZIS, Mary. Multiliteracies: new literacies, new learning. In: Pedagogies: an Internacional Journal, 4:3, 2009, p. 164,195. Disponível em https://www.researchgate.net/publication/242352947_Multiliteracies_New_Literacies_New Learning. Acesso em 15/03/2019.

DIONÍSIO, Ângela Paiva. Gêneros multimodais e multiletramento. In: KARWOSKI, A. M.; GAYDECZKA, B.; SIEBENEICHER, K. (Orgs.) Gêneros textuais: reflexões e ensino. Rio de Janeiro: Lucerna, 2008. p. 131-144.

FAIRCLOUGH, N. Discurso e mudança social. MAGALHÃES, I. (Coord. Trad.). Brasília: Universidade de Brasília, [1992] 2001.

FREIRE, Paulo. Ação cultural para a liberdade. $5^{\text {a }}$ ed., Rio de Janeiro: Paz e Terra, 1981.

GOMES, Luiz Fernando. Hipertexto no cotidiano escolar. São Paulo: Cortez, 2011.

HALLIDAY, Michael Alexander Kirkwood. Introduction to Functional Grammar, London: $\quad$ Edward $\quad$ Arnold, 2004. $\quad$ Disponível $\quad$ em http://www.uel.br/projetos/ppcat/pages/arquivos/RESOURCES/2004_HALLIDAY_MATTHI ESSEN An Introduction to Functional Grammar.pdf. Acesso em 14/08/2019.

HALLIDAY, M. A. K. Language as social semiotic: the social interpretation of language and meaning. London: Edward Arnold, 1978.

HALLIDAY, M. A. K. Explorations in the functions of language. London: Edward Arnold, 1973.

KRESS, Gunther. Literacy in the New Media. London: Routledge, 2003.

KRESS, Gunther. e van LEEUWEN, T. Reading Images: The Grammar of Visual Design. London: Routledge, 1996.

KRESS, G. et al. Multimodality. In: KRESS, G. et al. Multimodal teaching and learning. London: Continuum, 2001. p. 42-59.

LANKSHEAR, Colin; KNOBEL, Michele. A new literacies reader: educational perspectives (new literacies and digital epistemologies). New York: Peter Lang, 2013.

LANKSHEAR, Colin; KNOBEL, Michele. New Literacies: changing knowledge and classroom learning. 2. ed. Buckingham: Open University Press, 2003.

LANKSHEAR, Colin; KNOBEL, Michele. New Literacies: Everyday practices and classroom learning. 2. ed. Glasglow: McGraw-Hill/Open University Press, 2006.

LANKSHEAR, Colin; KNOBEL, Michele. Sampling "the New" in New Literacies. In: KNOBEL, Michele; LANKSHEAR, Colin (Eds.). A New Literacies Sampler. New York: Peter Lang, 2007. v. 29.

MAGALHÃES, I. Análise do discurso publicitário. Revista da ABRALIN, v. 4, n ${ }^{\circ} 1$ e 2, p. 231 a 260. Dezembro, 2005. Disponível em: http://www.abralin.org/revista/RV4N1_2/RV4N1_2_art8.pdf. Acesso em 23/05/2019.

MAIA, Kenia Soares. Nascer e crescer negro no país do branqueamento: os efeitos do racismo na subjetividade infantil. Tese (doutorado). Pontifícia Universidade Católica do Rio de Janeiro, Departamento de Psicologia, 2019. 145 f. Disponível em 
https://docplayer.com.br/147047581-Nascer-e-crescer-negro-no-pais-do-branqueamento-osefeitos-do-racismo-na-subjetividade-infantil.html. Acesso em 20/06/2019.

NASCIMENTO, Roseli Gonçalves, BEZERRA, Fábio Alexandre Silva, HEBERLE, Viviane Maria. Multiletramentos: iniciação à análise de imagens. Linguagem \& Ensino, Pelotas, v. 14, n. 2, Jul./Dez., 2011. Disponível em https://tamanini.com.br/wpcontent/uploads/2017/10///Multiletramentos-e-imagens.pdf. Acesso em 08/07/2019.

NEW LONDON GROUP. A pedagogy of multiliteracies: designing social futures. Harvard Education Review. V. 66, n. 1, 1996. Disponível em http://newarcproject.pbworks.com/f/Pedagogy+of+Multiliteracies_New+London+Group.pdf Acesso em 27/06/2019.

ROJO, Roxane. MOURA, Eduardo. Letramento, mídias e tecnologias. São Paulo: Parábola Editorial, 2019

SANDMANN, Antônio José. A linguagem da propaganda. 3 ed. São Paulo: Cortez, 1999. SANTAELLA, Lucia. Linguagens líquidas na era da mobilidade. São Paulo: Paulus, 2007. SANTOS, Záira Bomfante dos, PIMENTA, Sonia Maria Oliveira. Da semiótica social à multimodalidade: a orquestração de significados. CASA: Cadernos de Semiótica Aplicada, v.12, n.2, 2014, p. 295-324. Disponível em https://pdfs.semanticscholar.org/5ee1/01edc1cd65432e0da5a59cacfeed3391e6d5.pdf. Acesso em 19/06/2019.

SILVA, Nelma Teixeira da. A intertextualidade no gênero discursivo anúncio publicitário a partir da estratégia protótipo didático. Revista Philologus, Ano 21, $\mathrm{N}^{\circ} 63$ - Supl.: Anais da X CNLF. Rio de Janeiro: CIFEFIL, set./dez.2015. Disponível em http://www.filologia.org.br/rph/ANO21/63supl/012.pdf. Acesos em 12/05/2019.

TRAVAGLIA, Luiz Carlos. Da distinção entre tipos, gêneros e subtipos de textos. In: Estudos Linguísticos. Marília: São Paulo, 2001.

YARED, Maria Lílian de Medeiros. A ação semiótico-social da publicidade governamental sob a perspectiva da Análise de Discurso Crítica e da Multimodalidade. Tese (Doutorado). Universidade de Brasília, 2015. 3338 p. Disponível em https://pdfs.semanticscholar.org/bfb2/bc56ee0f7aefa14c5dd9736c403526195bef.pdf. Acesso em 24/06/2019. 